\title{
DISTRIBUIÇÃO QUANTITATIVA DE VARIÁVEIS DE QUALIDADE DA ÁGUA COLETADA EM DIFERENTES PONTOS DE UM PERFIL TRANSVERSAL DO RIO TURVO SUJO, MG
}

\author{
Flávia Mariani Barros ${ }^{1}$, Mauro Aparecido Martinez ${ }^{2}$, Atônio Teixeira de Matos 3 , Débora Astoni Moreira ${ }^{4}$
}

\begin{abstract}
RESUMO
Objetivou-se, com a realização do presente trabalho comparar a distribuição quantitativa de algumas variáveis de qualidade de água e verificar qual o local mais apropriado para coleta de água em uma seção transversal. Um perfil transversal do Rio Turvo Sujo, localizado no Estado de Minas Gerais, foi traçado e dividido em nove subseções nas quais foram realizadas coletas de água para quantificar as variáveis de qualidade. Para as variáveis condutividade elétrica, fósforo total dissolvido, fósforo inorgânico dissolvido, amônio e nitrato recomenda-se a amostragem a $20 \mathrm{~cm}$ de profundidade em relação à superfície com amostra composta por três pontos (esquerdo, central e direito); para as variáveis oxigênio dissolvido, turbidez, $\mathrm{pH}$, fósforo total, fósforo inorgânico dissolvido e nitrogênio total, recomendase a amostragem composta por três pontos (superfície, meio e fundo) na coluna central do curso d'água.
\end{abstract}

Palavras-chave: Coleta de água, locais de amostragem, poluição aquática.

\section{ABSTRACT \\ QUANTITATIVE DISTRIBUITION OF QUALITY VARIABLES OF WATER COLLECTED FROM DIFFERENT POINTS OF THE TURVO SUJO RIVER, MG}

The objective of this study was to compare the quantitative distribution of some water quality variables and to determine the most appropriate place for sampling in a cross section. A cross section profile of the Turvo Sujo River located in the Viçosa-MG district was selected and was divided into nine subsections to collect water samples for quantification of the quality variables. For quantifying electrical conductivity, total dissolved phosphorus, dissolved inorganic phosphorus, ammonium and nitrate, it is recommended that the samples should be collected to the depth of $20 \mathrm{~cm}$ from three points (left, centre and right), and for quantification of dissolved oxygen, turbidity, $\mathrm{pH}$, total phosphorus, dissolved inorganic phosphorus and total nitrogen, the samples should be collected from three points (surface, half and bottom) in the middle column of the water course.

Keywords: water collection, sampling locations, water pollution.

Recebido para publicação em 22/03/2010. Aprovado em 20/10/2011.

1- Agrônoma, Professora da UESB, mariamariani@yahoo.com.br

2- Agrônomo, Professor do DEA/UFV, mmauro@ufv.br

3- Engenheiro Agrícola, Professor do DEA/UFV, atmatos@ufv.br

4- Bacharel em Química, Professora da UEMG, deboraastoni@yahoo.com.br

60 REVENG 60-69 $\mathrm{p}$. 


\section{INTRODUÇÃO}

A qualidade da água pode ser representada por meio de diversas variáveis que traduzem as suas principais características físicas, químicas e biológicas. A poluição de um meio aquático pode causar alterações nas características físicas, tais como turbidez, cor, temperatura, viscosidade e tensão superficial; químicas, tais como demanda bioquímica de oxigênio (DBO), demanda química de oxigênio (DQO), potencial hidrogeniônico $(\mathrm{pH})$, oxigênio dissolvido (OD) e nutrientes; e biológicas, tais como eliminações de espécies de fitoplâncton e zooplâncton. A perda da qualidade da água pode comprometer o seu uso para agricultura, indústria, recreação e consumo humano (CRUZ, 2003).

Segundo esse mesmo autor, os rios são alimentados pelas águas de escoamento superficial, escoamento base e precipitação direta, sendo a maior parte do material em suspensão nas águas, proveniente de sua bacia hidrográfica. Assim, as águas dos rios devem refletir todas as características das bacias de drenagem, tais como litologia, geomorfologia, clima, solo e ação antropogênica.

Um sistema fluvial apresenta grande interação com os ecossistemas terrestres circunvizinhos, com importação e exportação de materiais e energia de maneira dinâmica (MARGALEF, 1983; HESPANHOL, 2009). Os rios são ambientes lóticos, ou de água corrente, sendo ecossistemas que apresentam renovação constante de vários tipos de substâncias. Consequentemente, são sistemas abertos, com fluxo contínuo desde a nascente até a foz (HYNES, 1970). As vazões de escoamento são grandes e as variáveis relacionadas à qualidade da água sofrem contínuas alterações temporais e espaciais em função das atividades antrópicas na bacia de contribuição. Isso torna o ambiente aquático muito instável, sendo, por essa razão, essencial a correta localização dos pontos para coleta de amostras de água, para caracterização da sua qualidade.

Na seleção do ponto para retirada das amostras de água, dois aspectos estão envolvidos: o local dentro do sistema e a posição exata no local escolhido (HYNES, 1970).

Os objetivos do programa de coleta de água definem, apenas aproximadamente, os locais para amostragem. Muitas vezes, de acordo com os objetivos da coleta é que se definem precisamente os locais de amostragem. Entretanto, quando os objetivos estabelecidos apontam apenas para uma indicação geral, como no caso do efeito de um efluente na qualidade de água de um rio, ou da avaliação da qualidade de água potável fornecida a uma comunidade, é necessário selecionar cuidadosamente os locais de amostragem apropriados (CETESB, 1988).

A Norma Técnica NBR 9897 (ABNT, 1987) dispõe sobre o planejamento de amostragem de efluentes líquidos e corpos receptores. Esta norma salienta que na escolha de uma seção de amostragem deve avaliar, a priori, se a distribuição de determinado poluente é homogênea; não sendo, devem ser realizadas amostragens que permitam definir o valor expectável da concentração na seção.

Não existe uma regra geral para demarcação de pontos de amostragem. Os critérios para sua demarcação assumem uma feição estratégica, ao depender do planejamento, do emprego do conhecimento e da realidade de campo, para detecção da vulnerabilidade de área para demarcação de pontos de amostragem (ABNT, 1987). Em geral não se devem retirar amostras próximo às margens dos rios, paredes de tubulações ou canais (exceto quando essas regiões são de interesse direto); pois a qualidade em tais pontos geralmente não é representativa de todo o volume de água, além de existir também a possibilidade de contaminação da amostra por materiais que se formam ou depositam nas margens ou fronteiras. Quanto mais à jusante o ponto de amostragem estiver de algum local de lançamento cíclico de resíduos, menor será a intensidade desse efeito (CETESB, 1988; ABNT, 1987).

Há duas causas principais da heterogeneidade da qualidade nos sistemas hídricos (CETESB, 1988): Sistema formado por duas ou mais águas de diferente composição que estão sem se misturar (estratificação térmica vertical em lagos e reservatórios) ou estão em processo de mistura (rio logo a jusante da descarga de um efluente ou tributário); distribuição não homogênea de determinadas substâncias em um sistema hídrico homogêneo. Novamente há dois casos a considerar: 
1) Materiais não dissolvidos que tendem a ficar heterogeneamente distribuídos se houver diferença entre a massa específica deles e a da água. Assim, o óleo tende a flutuar na superfície da água, enquanto os sólidos em suspensão tendem a se depositar; 2) Reações químicas ou biológicas que ocorrem em diferentes extensões, em diferentes partes do sistema como, por exemplo, o crescimento de algas nas camadas superiores do curso d'água com as consequentes mudanças em determinadas variáveis químicas, como $\mathrm{pH}$ e o oxigênio dissolvido.

As coletas de água são, geralmente, feitas na calha central do rio na profundidade de 15 a 30 cm (CETESB, 1988). Porém, a coleta realizada desta forma pode não suprir a necessidade de estudo para alguns casos específicos. Sendo, desta forma, necessário um estudo mais detalhado das variáveis de qualidade da água ao longo do perfil transversal de um rio.

Diante do exposto, o objetivo do presente trabalho foi comparar as variações de algumas variáveis de qualidade de água e verificar qual a melhor local para amostragem destas variáveis em uma seção transversal do Rio Turvo Sujo, localizada no município de Viçosa-MG.

\section{MATERIAL E MÉTODOS}

A área de estudo está localizada no Rio Turvo Sujo, pertencente à bacia hidrográfica do Rio Turvo Limpo. Esta bacia possui área total de 400,04 $\mathrm{km}^{2}$ e está compreendida entre as coordenadas geográficas $42^{\circ} 40^{\prime}$ e $43^{\circ} 00^{\prime}$ de longitude Oeste e 20 $39^{\prime}$ e $20^{\circ} 55^{\prime}$ de latitude Sul, abrangendo parte dos municípios de Viçosa, Cajuri, Coimbra, Teixeiras e Guaraciaba, no Estado de Minas Gerais. Apresenta altitude média de 775 metros, com cotas extremas de 600 e 945 metros (SANTOS, 2001).

A área apresenta rochas referentes ao período Pré-Cambriano inferior ou Indiviso, compreendendo gnaisses e magmatitos diversos. Sedimentos quaternários ocorrem ao longo dos vales, constituindo depósitos aluvionares de caráter argiloso, argilo-arenoso, representados por terraços e leitos maiores de deposição mais recente (CORRÊA, 1984).

O clima da região enquadra-se no tipo Cwa (clima inverno seco e verão chuvoso), de acordo com a classificação de Köppen, com temperatura do mês mais frio inferior a $18{ }^{\circ} \mathrm{C}$ e, do mês mais quente superior a $22{ }^{\circ} \mathrm{C}$ (BARUQUI, 1982).

Este estudo foi realizado no mês de Junho de 2007. A seção transversal estudada foi escolhida com base nas fontes de poluição, sendo a escolha feita em um trecho a jusante do encontro do Rio Turvo Sujo com o Ribeirão São Bartolomeu, o qual recebe a maior parte do esgoto gerado pela população da cidade de Viçosa-MG. A seção foi localizada a, aproximadamente, $300 \mathrm{~m}$ de distância do encontro do Rio turvo Sujo com o Ribeirão São Bartolomeu, sendo que este último deságua, em relação à Figura 1 (Seção do Rio Turvo Sujo), à direita.

A partir de então foi traçado o perfil da seção transversal do local escolhido e em seguida, de acordo com o perfil traçado foram selecionados os pontos para a coleta de água (Figura 1). Para a escolha destes pontos, a seção transversal foi dividida em três camadas, sendo cada uma destas subdividida em três resultando em nove subseções (Figura 1).

As amostras foram coletadas no ponto central de cada subseção feita no perfil (Figura 1) sendo realizadas três repetições em cada ponto.

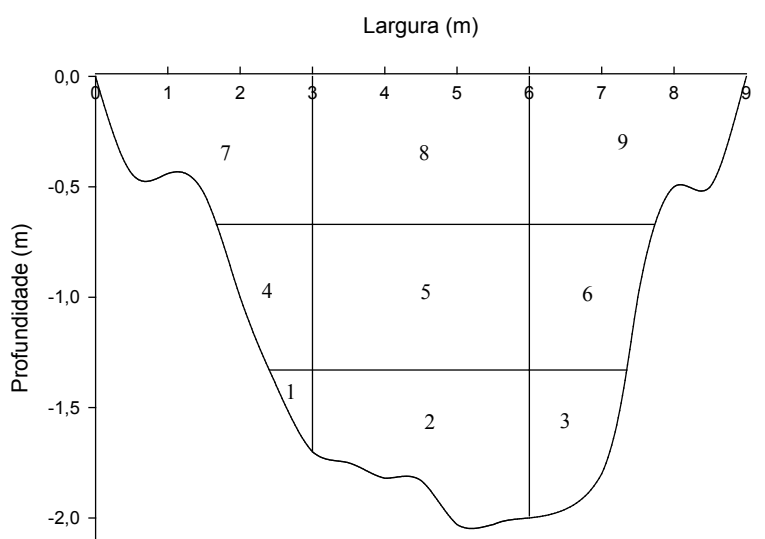

Figura 1. Esquema da seção transversal do Rio Turvo Sujo dividido em colunas e camadas e os respectivos pontos de coleta (1 a 9 ).

As amostras de água coletadas foram acondicionadas em caixas de isopor contendo gelo e imediatamente transportadas ao Laboratório de Qualidade da Água, do Departamento de Engenharia Agrícola da Universidade Federal de Viçosa. 
Em cada amostra de água coletada, quantificouse a concentração de nitrogênio total, amônio, nitrato, fósforo total, fósforo total dissolvido, fósforo inorgânico dissolvido, potencial hidrogeniônico, turbidez, oxigênio dissolvido e demanda bioquímica de oxigênio (DBO), segundo metodologias descritas em Matos (2004). O pH da água foi obtido pelo método eletrométrico, a turbidez foi medida utilizando-se um turbidímetro e a DBO foi quantificada utilizando-se o método Winkler (iodométrico). O nitrogênio total foi quantificado utilizando-se o método Kjeldahl, o amônio pelo método do salicilato (KEMPERS; ZWEERS, 1986), e o nitrato segundo o método descrito por Yang et al. (1998), fundamentadas no método colorimétrico. $\mathrm{O}$ fósforo total, o fósforo total dissolvido e o fósforo inorgânico dissolvido foram quantificados utilizando-se o método colorimétrico (APHA, 1995).

A velocidade do curso d'água foi determinada com o auxílio de um molinete, e a área da seção transversal por meio de levantamento batimétrico local, segundo metodologia descrita por Pruski et al. (2006). As posições do molinete para as determinações da velocidade média foram definidas de acordo com a profundidade do curso d'água (PRUSKI et al., 2006).

A partir dos resultados obtidos, foram feitas comparações (análise de variância e comparação de médias pelo teste de Tukey, adotando-se o nível de $5 \%$ de probabilidade utilizando-se o programa SAEG 5.0) individuais (pontos de 1 a 9); comparações por camadas: superfície (pontos 7 a 9), meio (pontos de 4 a 6 ) e fundo (pontos de 1 a 3 ); e comparações por colunas: esquerda (pontos $1,4 \mathrm{e}$ 7), central (pontos 2, 5 e 8) e direita (pontos 3, 6 e 9). Neste caso se considerou o valor médio de cada camada e coluna (Figura 1).

\section{RESULTADOS E DISCUSSÃO}

As variáveis de qualidade de água em cada ponto da seção transversal do Rio Turvo Sujo, quantificadas em laboratório, estão apresentadas no Quadro 1. No Quadro 2 estão apresentados os dados se considerando a seção dividida em camadas; e no Quadro 3, considerando-se a seção dividida em colunas.

\section{Oxigênio Dissolvido (OD) e Demanda Bioquímica de Oxigênio (DBO)}

De acordo com os resultados apresentados no Quadro 1, observa-se que houve grande variação na concentração de OD nos pontos da seção avaliada. Considerando a seção do Rio Turvo Sujo dividido em camadas, houve diferença significativa entre estas (Quadro 2) sendo a maior concentração de OD na superfície do rio, decrescendo com o aumento da profundidade.

Quando se dividiu a seção do rio em colunas (Quadro 3) não houve diferença significativa entre as concentrações de OD para as três colunas avaliadas, o que indica que o lançamento de poluentes não mais apresentava estratificação na qualidade da água.

Bambi e Pinto (2000) como objetivo de determinarem a produção primária do fitoplâncton e as relações com as principais variáveis limnológicas da Baía do Rio das Pedras-MT, no Estado do Mato Grosso, observaram que as maiores percentagens de saturação de oxigênio foram praticamente obtidas na superfície. Pacheco et al. (2004), com o objetivo de caracterizar as variações diárias de OD no reservatório da Hidrelétrica Serra de Mesa, observaram menores concentrações de OD com o aumento da profundidade.

A taxa de reintrodução de oxigênio dissolvido em águas naturais por meio da superfície depende das características hidráulicas e é proporcional à velocidade, sendo que a taxa de reaeração superficial em uma cascata é maior do que a de um rio de velocidade normal, que por sua vez, apresenta taxa superior à de uma represa, onde a velocidade normalmente é bastante baixa. Desta forma, como o oxigênio se encontra em contato direto com superficie da água e a velocidade nesta é maior $\left(0,65 \mathrm{~m} \mathrm{~s}^{-1}\right)$ que a do fundo do rio $(0,47 \mathrm{~m}$ $\left.\mathrm{s}^{-1}\right)$, evidentemente, a maior concentração de oxigênio se dará na camada superficial.

De acordo com os dados apresentados no Quadro 1, observa-se que houve grande variação na DBO quando se avaliou os pontos da seção separadamente. Este fato indica que a estabilização da matéria orgânica por meio de processos bioquímicos ocorreu de forma diferenciada em praticamente toda a seção transversal, o que pode ser devido à mistura entre as águas do Rio Turvo Sujo com as do Ribeirão São Bartolomeu não ter sido completa, ocasionando, desta forma, diferenças nesta variável. 


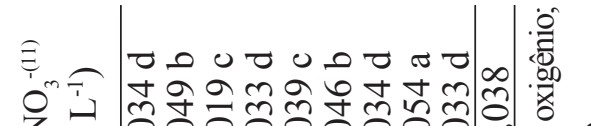

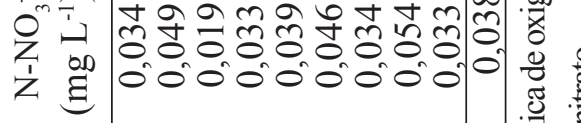

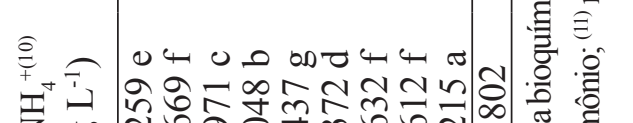
z.

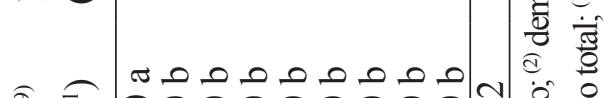
oิ Z 0.

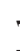

ह

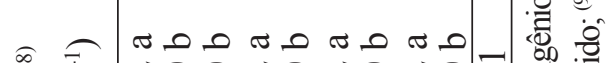

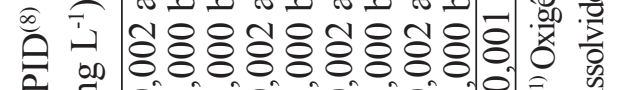

a E

年

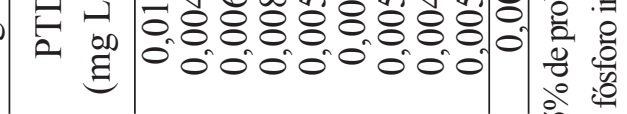

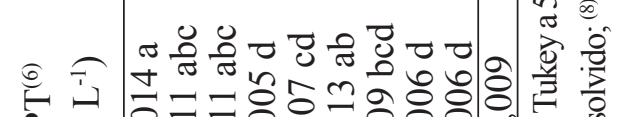

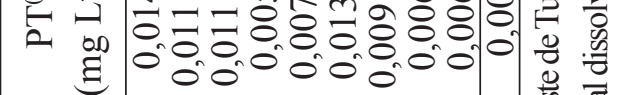

ล 0 م

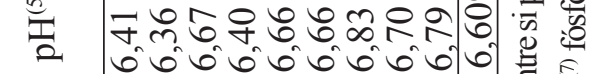

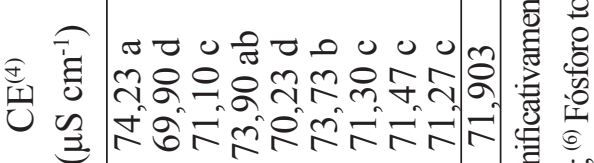

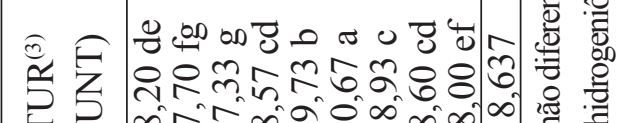

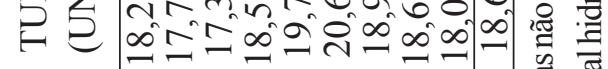

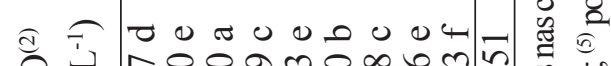

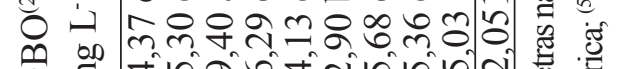

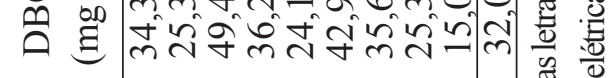

Є

苛

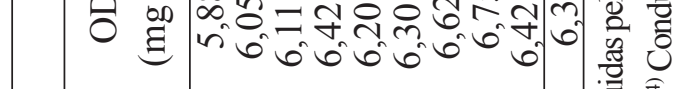

范

\section{REVENG}

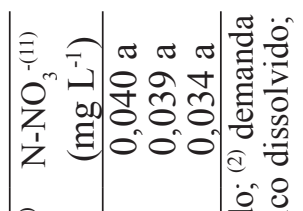

辛

洯

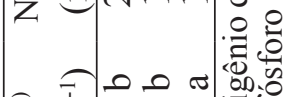

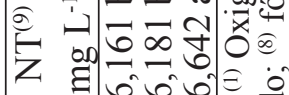

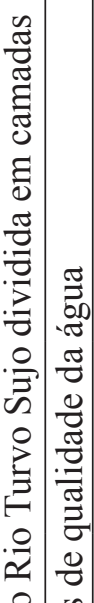

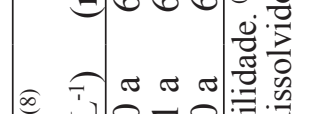

至

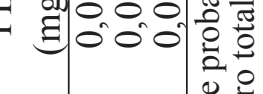

天

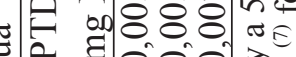

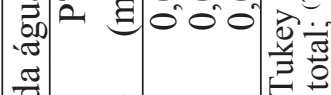

(ت)

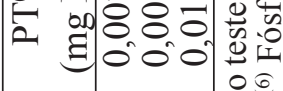

$\frac{n}{0}$

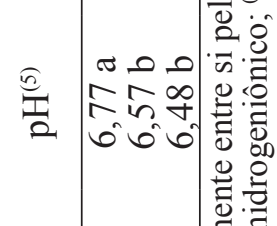

ช

至

م 0 0 0 0

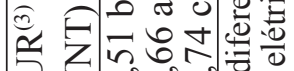

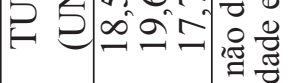

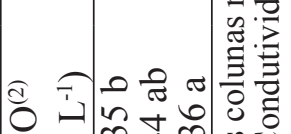

O 付

苚

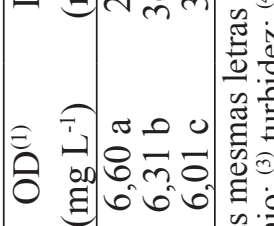

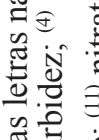

胥

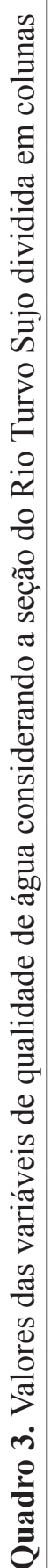

Є

○े

Z E

@) حำ

江

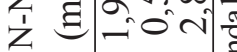

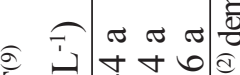

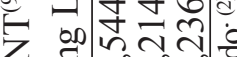

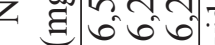

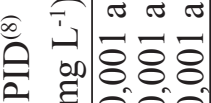

E్

秃

劣

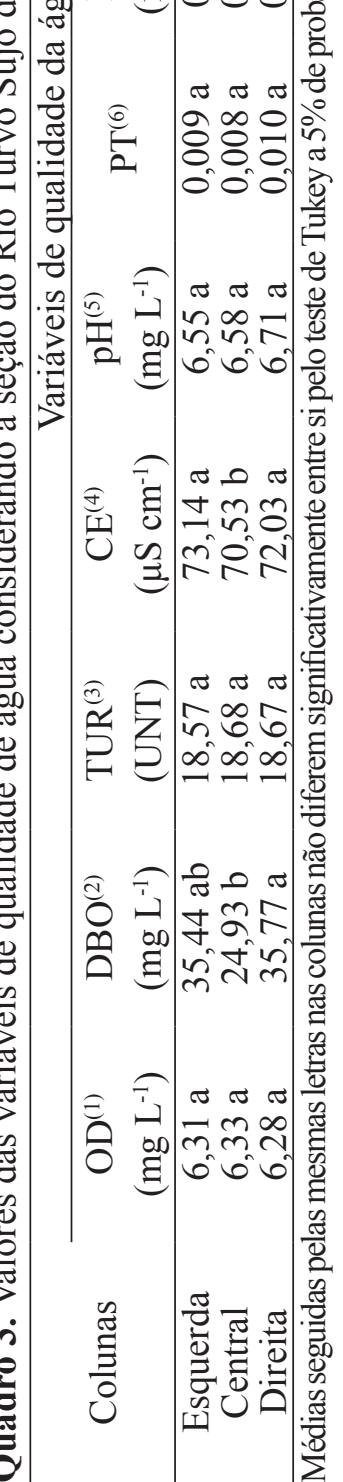

60-69 p.

ENGENHARIA NA AGRICULTURA, VIÇOSA - MG, V.20 N.1, JANEIRO / FEVEREIRO 2012 
Considerando a seção dividida em camadas (Quadro 2), observa-se que não houve diferença significativa entre as camadas do fundo e intermediária do rio; e entre as camadas intermediária e superficial do rio; sendo a maior DBO constatada nas camadas do fundo e intermediária. Isso pode ser devido à maior concentração de partículas que estão sendo sedimentadas para o fundo do rio, causando assim maior acúmulo de material orgânico e, consequentemente, aumento da DBO nestas áreas.

Segundo Von Sperling (1996) a matéria orgânica em suspensão que se sedimentou necessita ser também estabilizada. Apesar de grande parte desta estabilização se dar em condições anaeróbicas, a camada superior deste sedimento tem acesso ao oxigênio da massa líquida sobrenadante; portanto, nesta fina camada, a estabilização se dará aerobiamente, resultando no consumo de oxigênio. Ademais, alguns subprodutos parciais da decomposição anaeróbia podem se dissolver, atravessar a camada aeróbia do material orgânico sedimentado e se difundir na massa líquida exercendo uma demanda de oxigênio. Outro fator que pode causar consumo de oxigênio nas camadas inferiores do rio é a reintrodução, na massa líquida, da matéria orgânica anteriormente sedimentada, causada pelo revolvimento, sendo que este pode ocorrer em ocasiões de aumento de vazão.

Quando se dividiu a seção do rio em colunas (Quadro 3) observou-se que a DBO das colunas direita e esquerda não diferiram significativamente, sendo a concentração de DBO nessas áreas superiores à coluna central. Esse fato pode ser devido a essas colunas se localizarem próximas às margens do rio recebendo, assim, maior aporte de matéria orgânica e, consequentemente, ocasionando maiores valores de DBO nessas áreas. Além disso, as velocidades encontradas nas colunas esquerda e direita $\left(0,54 \mathrm{~m} \mathrm{~s}^{-1}\right)$ foram menores em relação à coluna central $\left(0,60 \mathrm{~m} \mathrm{~s}^{-1}\right)$, o que contribuiu para este resultado, já que a reaeração nas camadas laterais se processou mais lentamente que na central.

\section{Turbidez, Condutividade Elétrica (CE) e Potencial Hidrogeniônico (pH)}

De acordo com os dados apresentados no Quadro 1, observa-se que houve grande variação nos valores de turbidez quando se avaliou os pontos da seção separadamente.

Considerando a seção do Rio Turvo Sujo, dividida em três camadas, observa-se que houve diferença significativa entre estas (Quadro 2). Os maiores valores de turbidez ocorreram na camada intermediária, seguidos das camadas superficial e do fundo. Esses resultados indicam que a maioria das partículas, devido ao regime turbulento do rio, associado aos maiores valores de velocidade nas camadas superficial $\left(0,65 \mathrm{~m} \mathrm{~s}^{-1}\right)$ e intermediária, em relação ao fundo $\left(0,47 \mathrm{~m} \mathrm{~s}^{-1}\right)$, permaneceram em suspensão, contribuindo, desta forma, com o aumento da turbidez.

Quando se dividiu a seção do rio em colunas, observou-se que não houve diferença significativa entre as os valores de turbidez nas três colunas avaliadas (Quadro 3).

Os valores de $\mathrm{CE}$, quando avaliados de forma isolada dentro da seção do rio, apresentaram grande variação (Quadro 1), exceto para os pontos localizados na superfície deste.

Considerando a seção do Rio Turvo Sujo dividida em três camadas (Quadro 2), observase que não houve diferença significativa para os valores de CE entre estas, indicando, desta forma, que houve mistura dos íons dissolvidos durante todo o percurso do Rio Turvo Sujo e do Ribeirão São Bartolomeu.

Considerando a seção dividida em colunas (Quadro 3), observa-se que nas colunas esquerda e direita foram constatados maiores valores de CE em relação à intermediária. Isso provavelmente pode ser devido a essas colunas se localizarem próximas às margens do rio, recebendo assim, maior aporte de nutrientes do solo, o que pode ocasionar aumento nos valores de CE.

Os valores de $\mathrm{pH}$, quando avaliados de forma isolada dentro da seção do rio (Quadro 1), apresentaram pequena variação, sendo que os maiores valores de $\mathrm{pH}$ foram constatados nos pontos $3,5,6,7,8$ e 9 e menores nos pontos 1,2 e 4. Esse aumento do $\mathrm{pH}$ nos pontos citados pode 
ter ocorrido devido ao aumento da quantidade de matéria orgânica nestes locais, proveniente do deságüe do Ribeirão São Bartolomeu, que ainda não se misturou completamente na seção.

Considerando a seção do Rio Turvo Sujo dividida em camadas, observa-se que o $\mathrm{pH}$ na camada superficial foi maior em relação às camadas do fundo e intermediária (Quadro 2).

Quando se dividiu a seção do rio em colunas, observou-se que não houve diferença significativa (Quadro 5) entre as os valores de $\mathrm{pH}$ nas amostras de água das colunas avaliadas.

\section{Fósforo Total, Fósforo Total Dissolvido e Fósforo Inorgânico Dissolvido}

De acordo com os dados apresentados no Quadro 1, observa-se que houve grande variação nos valores das diferentes formas de fósforo quando se avaliou os pontos da seção separadamente.

Considerando a seção do Rio Turvo Sujo dividida em três camadas (Quadro 2), observase que não houve diferença significativa para os valores de fósforo total dissolvido e fósforo inorgânico dissolvido; porém, houve diferença significativa para os valores de fósforo total, sendo estes maiores no fundo do rio. Essa maior concentração de fósforo total no fundo do rio pode ser devido à sedimentação deste na coluna de água. Segundo Prada e Oliveira (2006) e Protázio et al. (2004), os sedimentos têm papel fundamental na ciclagem interna de nutrientes em ambientes aquáticos, pois a carga interna de nutrientes vinda destes pode ser da mesma ordem de magnitude ou até mesmo maior do que aquela advinda das entradas externas.

Quando se dividiu a seção do rio em colunas (Quadro 3), observou-se que não houve diferença significativa para os valores de fósforo total e de fósforo inorgânico dissolvido; já para os valores de fósforo total dissolvido houve diferença significativa, sendo este maior na coluna esquerda, resultado este que pode ter sido influenciado pelo maior aporte deste nutriente neste lado da seção. Segundo Mccallister et al. (2006), ao longo do curso dos rios, diversos processos físicos, químicos e biológicos podem alterar as formas geoquímicas originais destes compostos, consequentemente influenciando no potencial de retenção e exportação destes materiais no sistema, dependendo de sua associação às frações particulada, coloidal ou à dissolvida.

\section{Nitrogênio Total, Nitrato e Amônio}

De acordo com os resultados apresentados no Quadro 1, observa-se que houve grande variação na concentração de nitrato e amônio nos pontos da seção avaliada, sendo que o contrário ocorreu para os valores de nitrogênio total, que com exceção do ponto 1 , não houve diferença significativa para esta variável em relação aos outros pontos. A maior variação na seção, das variáveis nitrato e amônio, pode ser devido a estes serem elementos dinâmicos, alternando-se entre as várias formas e estados de oxidação, enquanto o nitrogênio total permanece inalterado.

Considerando a seção do Rio Turvo Sujo, dividido em camadas, observa-se que as camadas da superfície e intermediária apresentaram valores menores de nitrogênio total em relação à camada do fundo, o que pode ser devido aos sedimentos do fundo do rio, fato este também observado por Prada e Oliveira (2006). As variáveis amônio e nitrato não apresentaram diferença significativa (Quadro 2).

Quando se dividiu a seção do rio em colunas, não houve diferença significativa (Quadro 3) entre as concentrações de nitrogênio total para as três colunas avaliadas; os valores de amônio não apresentaram diferença significativa entre as colunas esquerda e direita, sendo estes maiores em relação à coluna central, o que pode ser devido a essas colunas se localizarem próximas às margens do rio recebendo, assim, maior aporte de matéria orgânica. Já a concentração do nitrato foi maior na coluna central do rio em relação às colunas esquerda e direita, fato este que pode estar relacionado à poluição mais remota concentrada na coluna central do rio em relação às margens (VON SPERLING, 1996).

Segundo Devens et al. (2006), no campo da modelagem da qualidade da água em rios, para descrever os mecanismos de transporte e dispersão de poluentes é necessário combinar o efeito da difusão molecular, responsável pela mistura devida 
ao movimento browniano das partículas, da difusão turbulenta, causada pela turbulência presente nos escoamentos naturais, e da advecção diferenciada, consequência da não uniformidade dos perfis de velocidade do escoamento.

A despeito do grau de complexidade envolvido na consideração dos efeitos determinantes no processo de transporte de massa em cursos de água naturais, a formulação matemática diferencial é bastante simplificada pela introdução do conceito de dispersão longitudinal. A diferença dos valores das variáveis de qualidade de água, apresentadas anteriormente, pode ser devido ao fato de que, segundo Fischer et al. (1979), o coeficiente de mistura turbulenta transversal é 40 vezes menor que o longitudinal devido, principalmente, aos gradientes de mistura transversais serem muito menores que os gradientes longitudinais. Além disso, ocorrem diferentes velocidades em uma mesma seção de um rio, o que ocasiona diferentes quantidades de partículas carreadas nos diferentes locais da seção transversal e, consequentemente, modificando os valores das variáveis de qualidade de água em cada ponto da seção.

\section{CONCLUSÕES}

- Houve grande variação das variáveis de qualidade da água quando se considerou a amostragem realizada em pontos isolados no perfil transversal do Rio Turvo Sujo;

- As variáveis condutividade elétrica, fósforo total dissolvido, fósforo inorgânico dissolvido amônio e nitrato não apresentaram diferença significativa entre camadas, quando analisouse a média dos valores das três subseções de cada camada; e

- As variáveis oxigênio dissolvido, demanda bioquímica de oxigênio, turbidez, potencial hidrogeniônico, fósforo total, fósforo inorgânico dissolvido e nitrogênio total não apresentaram diferença significativa entre colunas, quando analisou-se a média dos valores das três subseções de cada coluna;

Considerando a amostragem na calha central do rio a uma profundidade de aproximadamente $20 \mathrm{~cm}$ (ponto 8) e comparando-os com a média de todos os pontos da seção, a amostragem, apenas neste ponto, representaria erro em relação à média de $+7 \%$ para o OD, $-20,88 \%$ para a $\mathrm{DBO},-33,33 \%$ para o fósforo total e fósforo total dissolvido, $+100 \%$ para o fósforo inorgânico dissolvido, -66,04\% para o amônio e $+42,11 \%$ para o nitrato, sendo que para as variáveis turbidez, condutividade elétrica e nitrogênio total e $\mathrm{pH}$, os valores apresentariam diferença de $\pm 2 \%$;

Segundo os resultados obtidos recomenda-se que, para a situação em estudo, uma amostragem a $20 \mathrm{~cm}$ de profundidade em relação à superfície considerando amostra composta por três pontos (esquerdo, central e direito) para as variáveis condutividade elétrica, fósforo total dissolvido, fósforo inorgânico dissolvido, amônio e nitrato; já para as variáveis $\mathrm{OD}$, turbidez, $\mathrm{pH}$, fósforo total, fósforo inorgânico dissolvido e nitrogênio total, recomenda-se a amostragem composta por três pontos (superfície, meio e fundo) na coluna central do curso d'água.

\section{AGRADECIMENTOS}

Ao Conselho Nacional de Desenvolvimento Científico e Tecnológico (CNPq) pelas bolsas e auxílios concedidos.

\section{REFERÊNCIAS BIBLIOGRÁFICAS}

ABNT (Associação Brasileira de Normas Técnicas), 1987. Planejamento de amostragem de efluentes líquidos e corpos receptores - NBR 9897. Rio de Janeiro: ABNT.

APHA - AMERICAN PUBLIC HEALTH ASSOCIATION. Standard methods for the examination of water and wastewater. $19 \mathrm{Ed}$. New York: APHA, WWA, WPCR, 1995. 1134 p.

BAMBI, P.; PINTO-SILVA, V. Produção primária do fitoplâncton e as relações com as principais variáveis limnológicas da Baia das Pedras, Pirizal, Pantanal, MT. In: SIMPÓSIO SOBRE RECURSOS NATURAIS E SÓCIO-ECONÔMICOS DO PANTANAL, 3., 2000, Corumbá, MS. Resumos... Corumbá, MS: EMBRAPA PANTANAL, 2000. CD Rom. 
BARUQUI, F.M. Inter-relações solo-pastagem nas regiões da Mata e Rio Doce do Estado de Minas Gerais. 1982. 119 f. Dissertação (Mestrado em Solos e Nutrição de Plantas) - Universidade Federal de Viçosa, Viçosa, 1982.

CETESB (COMPANHIA DE TECNOLOGIA AMBIENTAL DO ESTADO DE SÃO PAULO). Guia de coleta e preservação de amostras de água. 1. ed. São Paulo, CETESB, 1988. 150p.

CORRÊA, G.F. Modelo de evolução e mineralização da fração de argila de solos do planalto de viçosa, MG. 1984. 86 f. Dissertação (Mestrado em Solos e Nutrição de Plantas) - Universidade Federal de Viçosa, Viçosa, 1984.

CRUZ, L.B.S. Diagnóstico ambiental da bacia hidrográfica do rio Uberaba - MG. 2003. $180 \mathrm{f}$. Tese (Doutorado em Água e Solo) - Universidade Estadual de Campinas, Campinas, 2003.

DEVENS, J.M.; BARBOSA JUNIOR, A.R.; DA SILVA, G.Q. Modelo de quantificação do coeficiente de dispersão longitudinal de pequenos cursos de água naturais. Engenharia Sanitária e Ambiental, Rio de Janeiro, v. 11, n. 3, p. 269276, jul/set. 2006.

FISHER, H.B.; LIST E.J.; KOH, R.C.Y.; IMBERGER, J.E BROOKS, N.H. Mixing in Inland and Coastal Waters. 1. ed. London: Academic Press, Inc, 1979. 465 p.

HESPANHOL, K.M.H. Monitoramento e diagnóstico da qualidade da água do Ribeirão Morangueiro. 2009. 85 f. Dissertação (Mestrado em Engenharia Urbana) - Universidade Estadual de Maringá, Maringá, 2009.

HYNES, H.B.N. The ecology of running waters. 3. ed. Liverpool: University Press, 1970. 555p.

KEMPERS, A.J.; ZWERS, A. Ammonium determination in soil extracts by the salicylate method. Soil Sci. Plant Anal. New York, v. 17, n. 7, p. 715-723. 1986.
MARQUES, M.O.; CORAUCCI FILHO, B.; BASTOS, R.K.X.; KATO, M.T.; LIMA, V.L.A. DE; ANDRADE NETO, C.O.; MENDONÇA, F.C.; MARQUES, P.A.A.; MARQUES, T.A.; BELLINGIERI, P.H.; VAN HAANDEL, A.C. Uso de esgotos tratados em irrigação: Aspectos agronômicos e ambientais. In: BASTOS, R. K. X. Desinfecção de efluentes sanitários, remoção de organismos patógenos e substâncias nocivas. Aplicações para fins produtivos como agricultura, aqüicultura e hidroponia. 1. ed. Viçosa: ABES, RiMa, 2003. p. 61-118.

MATOS, A.T. de. Práticas de qualidade do meio físico e ambiental. Viçosa: AEAGRI, 2004. 64 p. (Série Caderno Didático n. 34).

MARGALFF, R. Limnologia. 1. ed. Barcelona: Editora Omega, 1983. 1010p.

McCALLISTER, s. 1.; BAUER, J. E.; DUCKLOW, H.W. \& CANUEL, E.A.. Sources of estuarine dissolved and particulate organic matter: A multi-tracer approach. Organic Geochemistry. Inglaterra, v. 37, n. 4, p. 454-468, abril, 2006.

PACHECO, F.S.; CÉSAR, D.E.; ROLAND, F. Variação nictemeral de fatores abióticos no reservatório da UHE De Serra da Mesa/GO. In: SEMINÁRIO DE INICIAÇÃO CIENTÍFICA, 11., 2004, Juiz de Fora, MG. Resumos... Juiz de Fora, MG, 2004. CD Rom.

PRADA, S.M.; OLIVEIRA, E. Distribuição de nutrientes ( $\mathrm{C}, \mathrm{N}$ e $\mathrm{P}$ ) em testemunhos de sedimentos do reservatório das Graças, CotiaSP. In: REUNIÃO ANUAL DA SOCIEDADE BRASILEIRA DE QUÍMICA, 29., 2006, São Paulo. Resumos... São Paulo, 2006. p.108.

PROTAZIO, L.; TANAKA, S.M.C. N.; CAVALCANTE, P.R.S. Avaliação de procedimentos de extração seqüencial de fósforo em sedimento. Revta. Analyt., São Paulo, v. 8, n. 8, p. 35-41, dez/jan, 2004.

PRUSKI, F.F.; SILVA, D.D. da; KOETZ, M. Estudo de vazão em cursos d'água. Viçosa: 
AEAGRI, 2006. 151 p. (Série Caderno Didático n. 43).

SANTOS, A.R. dos. Caracterização morfológica, hidrológica e ambiental da bacia hidrográfica do rio Turvo Sujo, micro região de Viçosa, MG. 2001. 125 f. Tese (Doutorado em Engenharia Agrícola) - Universidade Federal de Viçosa, Viçosa. 2001.
VON SPERLING, M. Introdução a qualidades das águas e ao tratamento de esgotos. 2. ed. Belo Horizonte: DESA, 1996. 243p.

YANG, J.E.; SKOGLEY, E.O.; SCHAFF, B. E.; KIM, J.J.A. A simple spectrophotometric determination of nitrate in water, resin and soils extracts. Soil Sci. Soc. Am. J., New York, v. 62, p. 1108-1115, 1998. 